\title{
The Research on the Food Professional Association Introduced into Teaching and Scientific Research in Tarim University
}

\author{
Lixia Zhu \\ College of Life Science, \\ Tarim University, \\ Xinjiang, Alar, China \\ judyzhu1@sina.com \\ Zhiyang Zhang \\ College of Life Science, \\ Tarim University, \\ Xinjiang, Alar, China \\ 1335012209@qq.com
}

\author{
Fanglin Cui \\ Finance Department, \\ Tarim University, \\ Xinjiang, Alar, China \\ cuifanglin2008@163.com \\ Baoqiu Yang * \\ College of Life Science, \\ Tarim University, \\ Xinjiang, Alar, China \\ yangbaoqiu@163.com
}

\begin{abstract}
In the study, from the background, organization implementation and operation significance of the professional community, the case was to analyzed to introduce the food professional associations in teaching and scientific research in Tarim University. Food professional associations with inheritance, stability and persistence is both beneficial to the active learning and innovation of students and to the accumulation of professional knowledge of teacher. It eventually achieved the winwin result for teachers and students and the co-progress for teaching and scientific research.
\end{abstract}

Keywords-food professional association; Tarim University; teaching and research

\section{INTRODUCTION}

According to the dilemma of teaching and scientific research of Tarim University, the introduction of the professional association into teaching and research work was first carried out. Based on the resource advantage of the campus, projects from the college instructor and professional course teaching, the food professional association was set up by students majoring the food science and engineering. The features of highly collaboration, faith unity and fighting together of a professional association and the inherent characters of the innovation, system, goal-directed spirit and diversity training of a project will culture the senior technical personnel suitable for the demands of the era with creative feature and teamwork spirit, and drive the sustained development of course teaching and the common progress of teaching and the scientific research. The successfully created association of food profession would played a pilot role for other various professional associations how to construct and operate with valuable management experience.

\section{The BACKground OF CONSTRUCtion Of The FoOD PROFESSIONAL ASSOCIATION}

A. The Analysis of the Research Status, Development Trend of Domestic and Abroad of Professional Associations

At present, college students' associations speed faster to achieve the scale of development, the advantages and importance of professional associations for the talent cultivation in universities is gradually paid more attention to [13]. Professional association, besides inheriting characters of common associations, has strong professional background, strong atmosphere of innovation and entrepreneurship, lets academic research combine tightly and professional learning, and has professional practice, multi-disciplinary communication and professional expertise. In recent years with the review on the operation effect of general professional team, professional associations can significantly improve the professional level of the members and promote the formation of a good study style. Combining the science research, the project of entrepreneurship and employment, and expansion of the educational quality professional associations has the strong advantages to promote binding the production - study research, improve students' level of innovation and entrepreneurship, increase students' employment opportunities and enhance the construction of student moral quality and others [4-6]. Professional associations will become an important carrier of new stage of personnel training in universities.

Because of the professional associations in the initial stage in universities, research on professional associations mainly is focused on theoretical research, such as professional societies connotation, construction mode, mode of operation, quality guarantee system, however the practice cases is rarely. Before 2011, the professional associations mainly oriented liberal arts and accounted for the number of copies of total associations of less than $20 \%$, the professional associations of science and 
engineering are rarely more [7]. Putting forward "Education Excellence Program" by the Ministry of Education since 2011, all colleges and universities began to set up academic communities of science and engineering, but there is no related food professional associations. Our university now has not established the such associations, the professional societies are in the pipeline by Communist Youth League, in turn as an opportunity, the propose of cultivation of professional associations was put forward, in order to explore the model combining the professional societies, the professional teaching and science research.

\section{B. Theoretical Support}

College Students' professional associations refers to, in the university, the voluntary organization of students with a certain subject, a profession or a research direction according to their professional and interests. It is to meet the needs of members of professional knowledge as the basis, and to improve the academic level, practice ability and creative ability as the goal. Such a professional association has the common characteristics of student autonomy, self management, self service community in general. At the same time it has strong professional background, strong atmosphere of innovation and entrepreneurship, academic research combined tightly professional learning, the features of professional practice, multi-disciplinary communication and professional expertise. These all has been significantly and fully performed in the process of operation of the professional associations. The end goal is to improve the students' comprehensive professional quality and professional accomplishment, finally to help students to establish a scientific world outlook, outlook on life and values, to cultivate professional thinking, scientific spirit and humanistic spirit, to construct the spiritual home of architecture civilization. Based on the advantages above, the subject of professional societies was bold introduced into the practical teaching and scientific research to explore the mode combining professional associations, teaching and scientific research.

\section{Operation Pattern}

The professional association was based on food professional curriculum and teachers' scientific research project. The reasons are as follows: the content of teachers' scientific research is closely related to the professional curriculum, it is in practice and feasible to extract simple scientific experiment from teacher's scientific research to be as the practice teaching content in class. and of course practice teaching settings can consider the demand of the scientific research to service for scientific research. The two are melted into a professional learning community, will form a organic unity to promote each other. At the same time, the fusion of the two can strengthen the cultivation of professional associations.

Basic operation mode of the professional associations is professional students as main body under the macro management of the whole university, with professional teacher guidance and counselor assistance. From the long-term development perspective, on the basic operation mode, it was considering to joint university and related enterprise, study of curriculum and scientific research, employment and entrepreneurship, professional knowledge and moral education up to the all-round operation mode. Many factors influencing the quality of professional associations, including professional associations orientation, teachers, quality of community members, practice venues and equipment, community culture, community management institutions and rules, service system for numbers of association, community activities, sources of funds, etc. This community will carry on the organic connection of factors above as shown in Fig. 1 to ensure the quality of the professional associations

\section{The Organizational Structure Of The CONNOTATION OF THE FOOD PROFESSIONAL SOCIETIES}

\section{A. Instructor Groups Described}

The leading teacher group for planning and supervision and guidance.

The leaders from Educational department, scientific research department, School Youth League Committee, and other departments to master resources

The counselors group of executive guidance teachers: counselors

The coordinating teacher group: Laboratory management organizers

The professional teachers group: all the teachers with professional knowledge related to the projects of food professional association.

\section{B. Community Composition}

Association made up of the committee, organization department, Propaganda Department and project team

Including: the head of a committee, deputy head of an organization committee, a member for publicity. The committee is managed directly by the Federation of association of college students and supervised by the food science academy and other related department such as educational department.

The responsibility of head and deputy head of the professional association

(1), responsible for the overall work of community, the formulation of overall development planning, and leading the club to continue on;

(2), represents the association to deal appropriately with the school community, organization and the relation of the enterprise, provide a good external environment for the survival of the community;

(3), supervision, inspection, to guide our work;

(4), good financial management and document filing and meeting recording;

(5), do a good job in the community property daily management work;

(6), the rules and regulations of the formulation and implementation of the community.

(Note: head, deputy head have the close communication with leading group teachers) 
Organization Department, responsible for by the members of the organization, the organization committee duties:

(1), assists the deputy head, head to finish daily work;

(2), planning and execution of the community with head and deputy head

(3), planning, arrangement and organization of activities;

(4), to fully mobilize the enthusiasm, initiative and creativity of the members, organize and carry out the relevant work.

(Note: the organization department communicates directly with the coordinating teacher group)

The propaganda department is responsible for by the publicity committee, the publicity duties:

(1), assists the deputy head, head to deal with community daily work;

(2), planning and execution of the community with head and deputy head;

(3), the preparation and implementation of propaganda and publicity.

(Note: the propaganda department is mainly with the counselor teacher group)

The project team: all of the members in the food professional association to perform the science research work which is assigned as a project and has done by a project team.

\section{The Daily Operation of Food Professional Societies}

In addition to the committee, organization department, propaganda department to perform their duties (see organizational structure), the members of the association put more attention to the scientific research. with their own graduation design as the main task, they must enter the laboratory.

During the experiment, the members of the association give the weekly experimental follow-up report including the experimental progress, the experimental results, the problem and the solutions during the experimental process. The experiences and knowledge are shared and mutual exchanged between members.

Each month, invite the related professional teachers to give the guidance for experiment method, analyses and evaluation of results.

In each semester, there are two times activities out of laboratory and into factories relevant to the research work, to learn their ways of management of enterprises, to understand their production process, to obtain the current market demand information, the market demand of the product development or improvement.

In each semester, there is summary meeting, invite relevant teacher evaluation and guidance.

In each semester, there is the wine (especially Msalais) publicity around the whole campus at one to two times. The publicity forms has he poster, display panels, wine tasting, onsite Msalais development lecture and so on.

\section{The Effect Of Running The Food Professional}

\section{AsSOCIATION}

In theory, the professional associations can promote the practice of the development of teaching and scientific research. But at present the related effect of professional association on practical teaching and scientific research has not yet reported. In the food professional association, it chooses suitable scientific research project and practice of the teaching task to carry out to evaluate the effect of professional courses on the both teaching and scientific research, eventually to form the mode sustained n-depth development to promote the teaching of professional courses and scientific research.

College Students' innovative project in our university in recent years, has greatly encouraged the students' learning spirit, cultivated the students' interest in learning, at the same time strengthened the students' spirit of unity and cooperation in the project implementation process. All of these have proven that students in Tarim university have the ability of active learning, self management, unity and cooperation, constant innovation and etc. But such project is too small and too few to run through entire university learning process of a student with 4year academic study. At the same time as the end of the project, the project team automatically dissolved without persistence to provide continuous learning platform for students to truly study well the professional knowledge.

With the great increase of various scientific research project and the serious shortage of graduate students, the task of scientific research for teachers is increasing, this will result in scientific research over teaching situation. The teachers with no scientific research task are lack of interest and confidence to present or participate any scientific research, so, limited knowledge will be exhausted without innovation in teaching, it must be disadvantage for the development of Tarim university. Therefore, it was the first exploration of a new teaching mode to combine the professional associations, project research and practice teaching, relying on the resource advantage of Tarim university, projects of teachers and professional course teaching, mainly making up of the students majored the food science and engineering students. Because of the inheritance, stability, the professional association is beneficial to students persistently study with active learning attitude and innovative spirit, is also beneficial to the accumulation of professional teachers work. The ultimately effect of such teaching and learning mode would achieve win-win of students' and teachers', and common progress of teaching and scientific research.

\section{REFERENCES}

[1] Wang Jiadong, Ma Junyi. Effect of prpfessional associations in cultivating high skilled talents. Hebei Agricultural Sciences, 2011,02:148-149+155.

[2] Lu Dandan. The Analysis on University professional associations on the construction [J]. Journal of Lanzhou Institute of Education, 2013,05:7980.

[3] Yang Zhen. The analysis on the present situation and the development of university professional societies -- Taking Guangxi University For Nationalities as an example[J]. Management, 2014,07:137.

[4] Wang, Ma Qian.The integration modes of the professional associations based on three ways of " teaching, management, scientific research" [J]. textile industry and technology, 2014,02:73-74.

[5] Pang Guiping, Su Yi Hua. Training status and countermeasures of college student occupation ability based on the construction of college 
professional associations. modern rural science and technology[J], 2014,08:68-69.

[6] Mo Yuan, Chen Xiaobo. To strengthen the professional association construction to improve their competitiveness in employment [J]. Education Teaching Forum, 2014,33:194-196.
[7] Wang Wenjuan. on the thinking of the characteristics and development of university professional association[J]. China extramural education 2014,27:22.

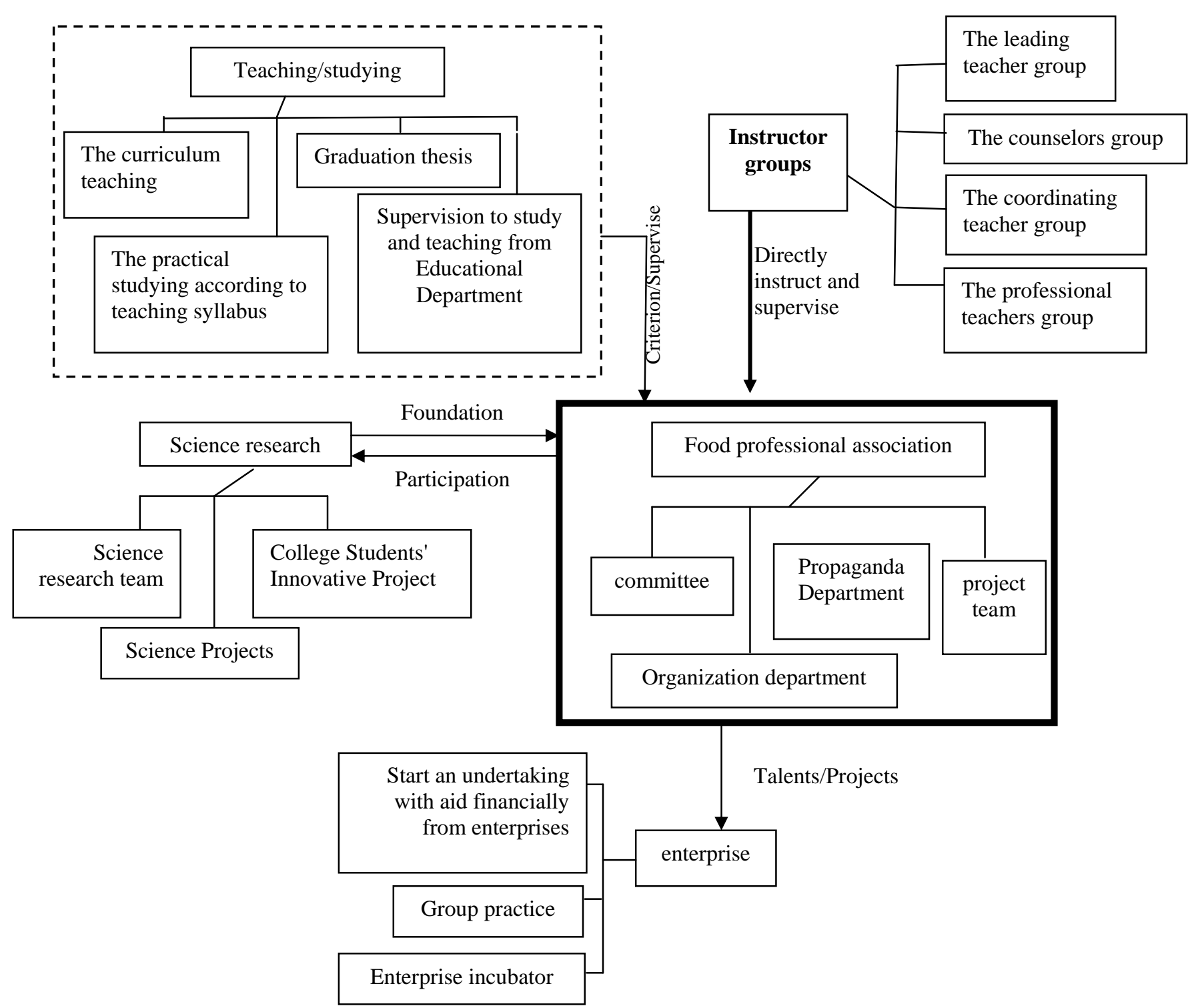

FIGURE 1 FOOD PROFESSIONAL ASSOCIATIONS ORGANIZATIONAL STRUCTURE AND PERIPHERAL CONTACT. 